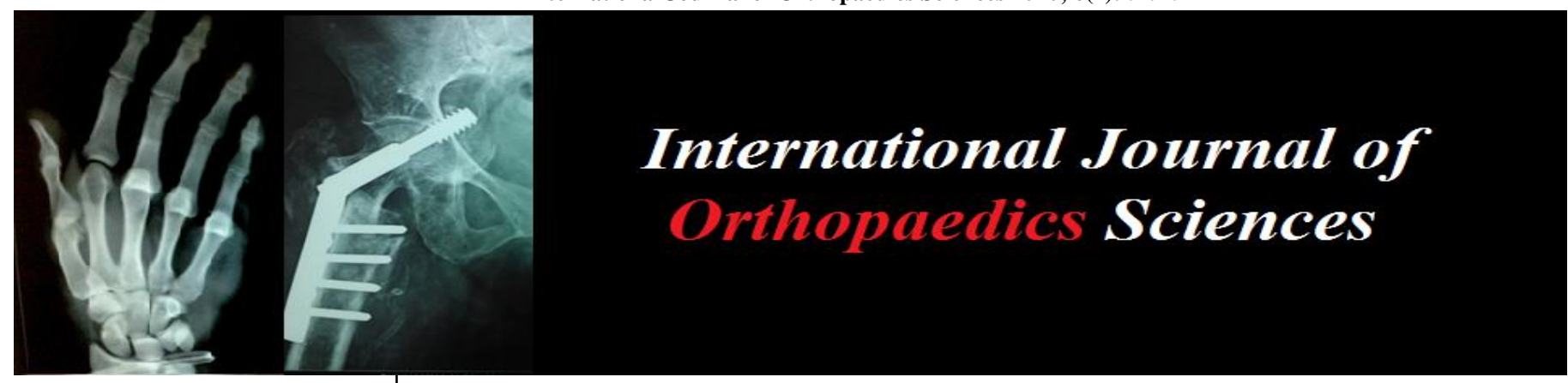

E-ISSN: 2395-1958

P-ISSN: 2706-6630

IJOS 2020; 6(4): 519-521

(C) 2020 IJOS

www.orthopaper.com

Received: 10-08-2020

Accepted: 13-09-2020

Dr. Arun Dungarwal

M.S. (Ortho), Consultant

Orthopedic Surgeon, Keshav

Porwal Hospital, Bhilwara

Rajasthan, India

Dr. Naresh Porwal

M.S. (Ortho) Director and Chief

Surgeon, Keshav Porwal

Hospital, Bhilwara Rajasthan,

India

\section{Functional outcome analysis for habitual patella instability treatment by MPFL advancement technique}

\section{Dr. Arun Dungarwal and Dr. Naresh Porwal}

DOI: https://doi.org/10.22271/ortho.2020.v6.i4h.2380

\section{Abstract}

Aim: Evaluation of functional outcome following medial patellofemoral advancement surgical procedure in habitual patellar dislocation.

Material and method: Prospective study was conducted in the department of orthopedic surgery at Keshav Porwal multispecialty Hospital, Bhilwara, Rajasthan among 24 patients from January 2018 to January 2020. All cases underwent proximal realignment surgery for habitual patellar dislocation with minimum follow-up of 6 months and maximum follow-up of 24 months. Radiological assessment was done using sulcus angle and congruence angle, pain was assessed with VAS scale.

Results: Mean age of the study group was 19.14 years. Among them $58.3 \%$ were male and $41.7 \%$ were female. Mean pre-operative sulcus angle was 132.06 degree and post-operative was 132.39 degree. Congruence angle pre-operative was 62.86 degree and post-operative was 17.81 degree. VAS score preoperatively and postoperatively were 6.16 and 3.01 respectively.

Conclusion: we conclude that following MPFL advancement surgery radiological parameters were brought back to normal anatomical position with painless functional outcome.

Keywords: habitual patella, MPFL advancement technique and radiological parameters

\section{Introduction}

Although patellofemoral joint instability symptoms are extremely common, there is still an incomplete understanding of the various interactions between different mechanical factors that control the movement and stability of patella ${ }^{[1]}$. There is complex Interplay between the active muscle tensions, the retinacular structure and reactive forces on the patellofemoral articular surface. The quadriceps muscle split in medial and lateral structures forming oblique attachment on patella surface acting as medial and lateral stablisers along with passive soft tissue structure medial patellofemoral ligament (MPFL) ${ }^{[2]}$.

Patellofemoralbony articular correlation is also an important factor for patellar stability. Habitual patellar dislocation is a rare condition where the patella dislocates during flexion and relocate during extension unlike chronic patellar dislocation that occurs during flexion and extension of the knee. Usually HPD are presents without pain and swelling. Incidence of HBD ranges from 6 per lakh in adults and 43 per lakh in pediatrics age group.

Etiology of habitual patellar disloctaorincludes contracture of quadriceps, Vastus lateralis, lateral retinaculum, abnormal iliotibial band attachment, repeated intramuscular injection in thigh region, genu valgum, patella alta, systemic ligamentous laxity and dysplastic lateral femoral condyle ${ }^{[3]}$.

Multiple surgical techniques has been advocated over the time with increase in our anatomical and bio physiological knowledge of knee musculoskeletal system. The patellar attachment of MPFL is usually wider from proximal medial border of patella extending upto of its length. The MPFL resides in the second layer of the three layers, below the deep fascia and superficial to the joint capsule, along with the superficial band of the medial collateral ligament. The patellar end of MPFL passes deep to the distal part of the Vastus medialis obliques (VMO) which overlay the MPFL at the patellar attachment and which is also attaches to the proximal part of the medial border of patella. Near to patellar attachment there is some merging of VMO deep fibers and MPFL fibers ${ }^{[4]}$.
Corresponding Author: Dr. Arun Dungarwal M.S. (Ortho), Consultant Orthopedic Surgeon, Keshav Porwal Hospital, Bhilwara

Rajasthan, India 
Most of the surgical procedures are focused on medial side soft tissue repair or reconstruction with or without lateral release. Our surgical technique of medial patella femoral advancement is focused more on anatomical placement of MPFL in its place to maintain correct transvers orientation.

\section{Material and methods \\ Study design}

The present study was conducted in the department of orthopedic surgery at the Keshav Porwal Multispecialty Hospital, Bhilwara, Rajasthan among 24 patients who underwent proximal realignment surgery for habitual patellar dislocation.

Ethical approval and informed consent: The study protocol was reviewed by local ethical committee.

\section{Inclusion criteria}

Patients 10-30 years of age group with habitual dislocation of patella.

\section{Exclusion criteria}

Age group below 10 yrs. and above 30 yrs.

Congenital knee deformity

Patients with other musculoskeletal diseases.

\section{Surgical technique}

Standard paramedial incision of $8 \mathrm{~cm}$ was made on the knee. Identify quadriceps tendon and its patellar attachment. Separate quadriceps tendon from patellar attachment without violating capsular layer. Dissect first and second layer along medial border of patella from capsular layer. Hold these two layers with braided absorbable suture. Next, subperiosteal dissection of capsular layer along medial border of patella exposing the articular surface done. Place two suture anchors in proximal and middle part of patella. Pass these nonabsorbable sutures from the capsular layer and tie the knots over capsular which advance the normal MPFL on patellar attachment. Pass the ends of these sutures from the soft tissue of patella and tie the knot in double breasting fashion. Close first and second layer with braided absorbable sutures in regular fashion over hemovac drain. Postoperatively, the knee is immobilized in long knee brace for 4 weeks and then rehabilitated.

\section{Outcome analysis}

Suture removal done after 15 days and cast applied in knee in 30 degree knee flexion for 30 days. After 30 days patients were assessed radiologically for sulcus angle and congruence angle. VAS scoringwas used for pain assessment.

\section{Statistical analysis}

The recorded data was compiled and entered in a spreadsheet computer program and then exported to data editor page of SPSS version. Descriptive statistics included computation of percentage. The Statical test applied for the analysis was paired t- test. The confidence interval and $\mathrm{p}$ - value were set at $95 \%$ and $\leq 0.05$ respectively.

\section{Results}

Table 1: demographic profile

\begin{tabular}{|c|c|}
\hline Age (years) & $19.14 \pm 2.59$ \\
\hline gender & $14(58.3) / 10(41.7)$ \\
\hline
\end{tabular}

Table 2: radiological outcome

\begin{tabular}{|c|c|c|}
\hline Radiological outcome & Pre-operative & Post-operative \\
\hline Sulcus angle & $132.06 \pm 6.43$ & $132.39 \pm 6.01$ \\
\hline p-value & \multicolumn{2}{|c|}{$>0.05$ (NS) } \\
\hline Congruence angle & $62.86 \pm 3.01$ & $17.81 \pm 3.42$ \\
\hline p-value & \multicolumn{2}{|c|}{$<0.05$ (Sig.) } \\
\hline
\end{tabular}

Test applied: paired t- test

Table 3: VAS score pre and post operatively

\begin{tabular}{|c|c|c|}
\hline \multirow{2}{*}{ VAS } & Pre operatively & Post operatively \\
\cline { 2 - 3 } & $6.16 \pm 1.31$ & $3.01 \pm 1.01$ \\
\hline p-value & \multicolumn{2}{|c|}{$<0.05$ (Sig.) } \\
\hline
\end{tabular}

Test applied: paired t-test

Table 4: recurrence of dislocation

\begin{tabular}{|c|c|}
\hline Recurrence & N (\%) \\
\hline Present & $4(16.7)$ \\
\hline Absent & $20(83.3)$ \\
\hline
\end{tabular}

\section{Discussion}

The concept of addressing the medial patellofemoral ligament in the treatment of patellar dislocation is not new. Sargent and Teipner [5] reported excellent results in 14 patients who underwent repair of the medial patellar retinaculum following acute patellar dislocation. Acute repair of the medial patellofemoral ligament has also been advocated by Boden $e t$ al. ${ }^{[6]}$

More recently, Fithian and Meier [7] have described their technique for advancement and repair of the medial patellofemoral ligament and provided rationale for procedures that address the essential pathoanatomy of patellar dislocation. They emphasize that realignment of the dynamic patellar stabilizers, i.e., distal realignment procedures; do not address the damaged medial structures.

The present prospective study was conduct over 24 patients who underwent surgery for habitual patella dislocation and were examined pre operatively and one month after post operatively. There is no significant changes in sulcus angle as trochleoplasty procedure was not done and there was inadequate study time too notice bony changes in growing patients.

Radiologically there was a significant change in congruence angle. VAS score was also significantly improved. Two of our cases had, recurrence, one was revised with modified Galeazzi's technique and other one with modified Roux Goldthwait procedure. This was found in agreement with the study conducted by Drez D et al. ${ }^{[8]}$ in 2001 showed that radiographically, the mean (6 standard deviation) congruence angle (normal $217^{\circ}$ to $15^{\circ}$ ) improved from $25.3^{\circ}\left(618.7^{\circ}\right)$ (range, $0^{\circ}$ to $\left.66^{\circ}\right)$ preoperatively to $5.5^{\circ}\left(68.0^{\circ}\right)$ (range, $210^{\circ}$ to $\left.20^{\circ}\right)$ at latest follow- up $(P<0.0006)$.

\section{Conclusion}

The present study concludes that Mediopatello femoral advancement (MPFL) is a safe and effective procedure for treating habitual patellar dislocation. Future study to quantify a medial laxity (amount of medial soft tissue to be imbricated and/or additional dynamisation stabilization procedure) is desirable.

\section{References}

1. Loudon JK. Biomechanics and pathomechanics of the patellofemoral joint. Int $J$ Sports Phys Ther 2016;11(6):820-30. 
2. Andrikoula S, Tokis A, Vasiliadis HS, Georgoulis A. The extensor mechanism of the knee joint: an anatomical study. Knee Surg Sports Traumatol Arthrosc 2006;14(3):214-20.

3. Hayat Z, El Bitar Y, Case JL. Patella Dislocation. [Updated 2020 Jul 10]. In: StatPearls [Internet]. Treasure Island (FL): StatPearls Publishing 2020. Available from: https://www.ncbi.nlm.nih.gov/books/NBK538288/

4. Krebs C, Tranovich M, Andrews K, Ebraheim N. The medial patellofemoral ligament: Review of the literature. J Orthop 2018;15(2):596-99.

5. Sargent JR, Teipner WA. Medial patellar retinacular repair for acute and recurrent dislocation of the patella. A preliminary report. J Bone Joint Surg Am 1971;53:386.

6. Boden BP, Pearsall AW, Garrett WE, Feagin JA. Patellofemoral instability: Evaluation and management. J Am Acad Orthop Surg 1997;5:47-57.

7. Fithian DC, Meier SW. The case for advancement and repair of the medial patellofemoral ligament in patients with recurrent patellar instability. Oper Tech Sports Med 1999;7:81-89.

8. Drez D Jr, Edwards TB, Williams CS. Results of medial patellofemoral ligament reconstruction in the treatment of patellar dislocation. Arthroscopy 2001;17(3):298-306. 